\title{
ROTULAGEM AMBIENTAL E GREENWASHING: ANÁLISE DE DISCURSOS E PRÁTICAS EMPRESARIAIS
}

\author{
Renata Silva Araújo \\ Graduada em Gestão Ambiental, Universidade de São Paulo - USP, Brasil. \\ renata_arauj0459@yahoo.com.br
}

\section{SYLMARA LOPES FRANCELINO GONÇALVES DIAS}

Doutora em Administração, Escola de Administração de Empresas de São Paulo da Fundação Getúlio Vargas EAESP/FGV, Brasil.

Doutora em Ciência Ambiental, Universidade de São Paulo - USP, Brasil.

Professora Associada da Escola de Artes, Ciências e Humanidades, Universidade de São Paulo - USP, Brasil sgdias@usp.br

\section{ÉRICO LUCIANO PAGOTTO}

Doutorando no Programa de Pós-Graduação em Sustentabilidade, Universidade de São Paulo - USP, Brasil. Professor da Faculdade de Jacareí e da Faculdade Anhanguera, Brasil.

ericopagotto@usp.br

\begin{abstract}
Resumo
Com a finalidade de obter ganhos mercadológicos, muitas empresas utilizam a rotulagem ambiental para valorizar suas marcas e produtos. Contudo, é importante que tal comunicação esteja pautada em critérios éticos e técnicos para garantir a credibilidade destas declarações. Este estudo discute tal questão a partir da seguinte pergunta: a rotulagem ambiental condiz com as práticas adotadas pela empresa estudada, ou trata-se somente de greenwashing? 0 método consistiu em analisar o rótulo e as práticas ambientais de um produto por meio de dados secundários e entrevistas semiestruturadas. Os resultados apontam que a rotulagem e as práticas ambientais adotadas pelo fabricante estão parcialmente alinhadas. Também se identificou que a embalagem apresenta elementos passiveis de contestação, com informações ambiguas e por vezes exageradas. As evidências demonstram que o rótulo pode estar sujeito a questionamentos considerando-se tanto as normativas aplicáveis como em sua capacidade de informar adequadamente ao público consumidor.
\end{abstract}

Palavras-chave: responsabilidade social, rotulagem ambiental, comunicação ambiental, greenwashing. 


\title{
GREEN LABELLING AND GREENWASHING: DISCOURSE ANALYSIS AND BUSINESS PRACTICES
}

\begin{abstract}
For commercial reasons many companies adopt green labeling to increase value for their brands and products. However, it is important that this kind of communication is linked to ethical and technical criteria in order to endorse the credibility of its statements. This study discusses such matter from the following question: does the Green Labelling match the adopted practices by the studied company, or it is only about greenwashing? The method consisted in analyzing both labels and environmental practices of a product through secondary data and semi-structured interviews. Results indicate that labelling and environmental practices adopted by the company are partially aligned. It was also noted that the packaging presents elements that can be possibly contested, with ambiguous and sometimes exaggerated information. Evidences show that the label may be contested, considering the applicable regulations as well as its ability to properly inform its consumers.
\end{abstract}

Keywords: social responsibility, environmental labelling, private organizations, greenwashing.

\section{ROTULO AMBIENTAL Y GREENWASHING: ANÁLISIS DE DISCURSOS Y PRÁCTICAS EMPRESARIALES}

\begin{abstract}
Resumen
Con el fin de obtener ganancias mercadológicas, muchas empresas utilizan el rotulo ambiental para valorizar sus marcas y productos. Sin embargo, es importante que dicha comunicación esté pautada en criterios éticos y técnicos para garantizar la credibilidad de estas declaraciones. Este estudio discute tal cuestión a partir de la siguiente pregunta: ¿El rotulo ambiental condice con las prácticas adoptadas por la empresa estudiada, o se trata solamente de greenwashing? El método consistió en analizar el rotulo y las prácticas ambientales de un producto a través de datos secundarios y entrevistas semiestructuradas. Los resultados apuntan que el rotulo y las prácticas ambientales adoptadas por el fabricante están parcialmente alineadas. Se identificó que el embalaje presenta elementos pasibles de contestación, con informaciones ambiguas y a veces exageradas. Las evidencias demuestran que el rótulo puede estar sujeto a cuestionamientos considerando las normativas aplicables y en su capacidad de informar adecuadamente al público consumidor.
\end{abstract}

Palabras clave: responsabilidad social, rotulo ambiental, organizaciones privadas, greenwashing. 


\section{INTRODUÇÃO}

A partir do desenvolvimento industrial acelerado na segunda metade do século XX, as questões socioambientais vêm sendo incorporadas ao meio empresarial de diversas formas. Assim, revisões de processos, gerenciamento de resíduos, investimentos em qualidade de vida no trabalho, certificações, rotulagens e uma série de outras medidas têm sido adotadas por muitas empresas não apenas para o cumprimento de normas legais, mas também de forma estrategicamente proativa como parte integrante de suas políticas de gestão, produção e comunicação. O conjunto destas ações constitui a chamada "responsabilidade corporativa", atualmente um campo de conhecimento consolidado (Blowfield \& Murray, 2008; Werther \& Chandler, 2006) e em expansão (Egri \& Ralston, 2008), ainda que bastante fragmentado (Eteokleous, Leonidou, \& Katsikeas, 2016). A inserção da temática socioambiental nas organizações privadas, no entanto, abre espaço para um debate acerca do conteúdo dessas práticas de responsabilidade, em particular na forma como se dá a comunicação entre empresas e sociedade. Este é o cenário no qual o presente artigo se insere.

Estratégias corporativas influenciam no tipo de informação que é divulgada e nos impactos que cada uma pode vir a causar para determinados stakeholders. Assim, por exemplo, organizações com fraco desempenho ambiental podem ter maior probabilidade de fazer uma triagem dos dados que serão divulgados, afetando diretamente sua reputação e credibilidade (Marquis, Toffel, \& Zhou, 2015). Neste contexto, a comunicação ambiental organizacional refletiria os valores empresariais (Brito, 2013), e a partir daí a rotulagem referente a atributos ambientais vem sendo usada para comunicar e ressaltar aos clientes que o produto possui elementos que supostamente Ihes oferecem algum tipo de vantagem ou benefício (Bratt, Hallstedt, Robert, Broman, \& Oldmark, 2011; de Boer, 2003).

De acordo com Whitson, Ozkaya e Roxas (2014), embora haja registros da adoção de apelos ambientais na divulgação de marcas e produtos pelo menos desde 1959, foi a partir da década de 1990 que este movimento ganhou força em decorrência da adoção de práticas de responsabilidade social por um número maior de empresas. Foi neste mesmo período que foram propostas normatizações para os chamados "eco-labels", ou "certificações ambientais", tanto nos Estados Unidos (Federal Trade Comission [FTC], 1992) como na União Europeia (Organisation for Economic Co-operation and Development [OECD], 1997) justamente para diferenciar os produtos que atenderiam a determinados requisitos (sendo, portanto, "certificados") daqueles que fariam meras alegações de desempenho com rótulos ou embalagens "verdes".

Segundo Wells (2006, p. 350), a rotulagem ambiental representa, ao mesmo tempo, uma das ferramentas para a mudança dos hábitos das pessoas e uma das armas mais perigosas para enganar o consumidor sobre o real impacto do produto que está prestes a usar. Como indicam Hainmueller e Hiscox (2015), a rotulagem ambiental tem potenciais benefícios tanto para fornecedores, que podem voluntariamente aderir ou não a estratégias que lhe confiram vantagens comerciais, como para compradores, que poderiam fazer uma escolha mais bem informada. Se, por um lado, pesquisas sobre efeitos do impacto da rotulagem ambiental na intenção de compra permanecem inconclusivas (Whitson, Ozkaya, \& Roxas, 2014), por outro lado, há sinais de certo impacto positivo na percepção do consumidor sobre produtos que apresentam mensagens ambientais (Borin, Cerf, \& Krishnan, 2011).

Uma vez que há uma banalização de expressões que remetem à sustentabilidade e às questões socioambientais e, ao mesmo tempo, há pouca regulamentação sobre estas formas de comunicação, é importante analisar as práticas empresariais para além dos rótulos e propagandas, de forma que se possa verificar em que medidas discursos e práticas estão alinhados entre si. Marquis, Toffel e Zhou (2015) atentam para o fato de que nem sempre a comunicação ambiental

OS, Organizações e Sustentabilidade, 7(2), p. 25-42, Londrina, PR, jul./dez. 2019.

ISSN 2318-9223, http://www.uel.br/revistas/uel/index.php/ros/issue/view/1607/showToc 
de uma empresa é um retrato fiel de suas práticas e ações. Deste modo, este estudo buscou responder à seguinte pergunta: a rotulagem ambiental presente no produto selecionado para estudo condiz com as práticas adotadas pela empresa, ou trata-se somente de greenwashing?

O greenwashing consiste em qualquer ação de propaganda, marketing ou relações públicas utilizada pelas empresas para projetar uma imagem de uma organização orientada para o ambiente, mesmo quando suas práticas de negócios sejam consideradas danosas e destrutivas (Ihlen et al., 2011). Embora haja registros de sua ocorrência desde a década de 1960 (Karliner, 2001), foi apenas a partir dos anos 1990 que o fenômeno começou a ser estudado de forma mais sistemática (Creenpeace, 1992; Tokar, 1997; Greer \& Bruno, 1997; Lubbers, 2002).

0 ponto importante a respeito do greenwashing é que ele promove uma distorção da realidade e afeta negativamente a capacidade do cidadão de fazer suas escolhas de forma autônoma. Há, no entanto, uma dificuldade de regulação deste tipo de comunicação enganosa por dois motivos: primeiro, em função das dificuldades técnicas e semânticas envolvidas na caracterização objetiva do greenwashing, e segundo porque há uma deliberada confusão invocada entre liberdade da publicidade comercial e liberdade de imprensa e que na prática tem justificado a autoregulamentação como alternativa conciliatória possível (Bucci, 2008; Bucci \& Augusto Jr, 2012), ainda que questionável do ponto de vista ético e ideológico (Pagotto, 2013). Pesquisas e princípios em torno da regulação dos elementos que caracterizam o greenwashing ainda são escassos e muitas vezes baseados em intuição e expertise profissional (Antoniolli \& Gonçalves-Dias, 2015). Dessa forma, busca-se trazer contribuições para analisar os discursos e as práticas ambientais das organizações, identificando contradições, oportunidades e possibilidades de melhorias.

\section{REFERENCIAL TEÓRICO}

\section{EXISTEM PRODUTOS ECOLOGICAMENTE CORRETOS?}

É certo que para uma empresa agir como promotora do desenvolvimento sustentável precisará ir além de práticas ambientalistas como plantar árvores, economizar água, entre outras (GonçalvesDias \& Teodósio, 2011). Ou seja, o direcionamento das empresas rumo à sustentabilidade não consiste em práticas simples, embasadas somente em acompanhamento, mitigação e compensação dos impactos ambientais. A sustentabilidade requer mudanças no modo de produção e consumo, bem como um novo posicionamento empresarial coerente com as novas demandas sociais.

A respeito da sustentabilidade na produção e no consumo devem-se considerar ainda outras questões. Primeiro, os efeitos ecossistêmicos da produção sobre a natureza não são plenamente conhecidos, e, portanto mensuráveis; segundo, a indisponibilidade de conhecimento pleno a respeito dos impactos sobre o meio suscita reflexões a respeito do princípio da precaução; terceiro, a extração de recursos naturais em demasia afeta a sua disponibilidade, comprometendo sua utilização por gerações futuras; e por fim, a avaliação de impactos da produção de bens tem focado muito mais em questões objetivas e materiais da cadeia de abastecimento, e menos em seus efeitos culturais e subjetivos mais pela dificuldade técnica de fazê-lo do que devido à sua importância.

Neste sentido, Kazazian (2005) diz que, fundamentalmente, não existem produtos "ecológicos". Cada uma das etapas da vida do produto gera entradas e saídas que resultam em impactos sobre 0 meio ambiente. Essas etapas devem ser analisadas desde a concepção do produto, porque cada uma contém um potencial de otimização ambiental, ligados à escolha das matérias-primas, das tecnologias e processos de fabricação, à organização da logística, ao contexto de uso e à valorização final do produto (Gonçalves-Dias, Guimarães, \& Santos, 2012). Daí a importância dos

OS, Organizações e Sustentabilidade, 7(2), p. 25-42, Londrina, PR, jul./dez. 2019.

ISSN 2318-9223, http://www.uel.br/revistas/uel/index.php/ros/issue/view/1607/showToc 
setores produtivos assumirem efetiva responsabilidade sobre os impactos sociais e ambientais negativos de sua produção para além do que afirmam certos discursos publicitários.

Ainda que muitas peças publicitárias insistam na oferta de produtos "ecológicos" ou "verdes", a ocorrência de impactos negativos sobre o ambiente é inequívoca e muitas vezes irreversível. No caso de bens materiais, tais danos estão inseridos dentro das cadeias de produção que incluem processos que vão desde a extração da matéria-prima, passando pela distribuição, comercialização e indo até o descarte do produto final, gerando, a depender de seus respectivos contextos, maior ou menor impacto ambiental (Gonçalves-Dias, Guimarães, \& Santos, 2012). Tal fato reforça a necessidade de mudanças nos modos de produção e consumo com a finalidade de evitar ou minimizar danos ambientais e sociais, ampliando a importância de estudos sobre rotulagem ambiental no cenário brasileiro.

\section{ROTULAGEM AMBIENTAL, AUTO-REGULAMENTAÇÃO E LEGISLAÇÃO}

Os rótulos auxiliam no esforço promocional de uma organização, sendo uma parte importante da embalagem de um produto. Rótulos servem para identificar e descrever os atributos e características dos produtos. Como afirmam Churchill e Peter (2012, p. 284), os rótulos podem dar suporte ao marketing, promovendo o produto e acrescentando valor para o cliente ao oferecer informações que o ajude na seleção e no uso do produto. Para alguns produtos, o governo já exige que os rótulos contenham informações específicas, mas ainda não regulamenta os rótulos com apelos ambientais.

Wells (2006, p. 350) diz que a rotulagem ambiental "consiste nas declarações que constam nos rótulos ou folhetos e anúncios de produtos, indicando seus atributos ambientais". É importante ressaltar que certificação ambiental não é sinônimo de rotulagem ambiental, e que estes dois elementos nem sempre estão ligados. Assim, a rotulagem ambiental fornece informações sobre o produto ou serviço e pode estar ligada à certificação quando se tratar de selo verde; pode não ter vínculo com a certificação quando se tratar de uma autodeclaração realizada pela empresa (Valle, 2004). Contudo, as rotulagens ambientais com certificação (selo verde) e sem certificação (autodeclaração) devem estar alinhadas às normas estabelecidas pela NBR ISO 14020 (Associação Brasileira de Normas Técnicas [ABNT], 2002), pelo Código de Defesa do Consumidor (Brasil, 1990) e pelo código do CONAR - Conselho Nacional de Auto-regulamentação Publicitária (CONAR, 2016), que tratam com especificidade os tipos de rotulagem aplicáveis.

É prudente citar que as certificações ambientais, que são mecanismos voluntários de diferenciação de produtos, serviços e organizações com base em normas legais ou táticas comerciais, também possuem falhas, sendo criticadas em alguns aspectos por vários autores (Kirchhoff, 2000; Kleba, 2003; Traies, 2005; Silva, 2011). Há uma crescente literatura que examina as circunstâncias em que as empresas voluntariamente divulgam informação ambiental e a necessidade de normas e verificação de terceiros para orientar as empresas sobre o que os indicadores ambientais deveriam comunicar (Kolk, 2004; Reid \& Toffel 2009).

O CONAR criou um Código Brasileiro de Auto-regulamentação Publicitária como instrumento de autodisciplina da atividade. O Conselho tem buscado coibir manifestações de greenwashing a partir do estabelecimento e aplicação de seu código de regulação em peças publicitárias especificamente em seu "Anexo U", que trata das publicidades com apelos ambientais e que, em alguns itens, reforça os requisitos das normas ISO já citadas, assim como reafirma algumas exigências estabelecidas no Código de Defesa do Consumidor - CDC (Brasil, 1990), como a necessidade de informações corretas, claras e precisas, sendo proibida qualquer publicidade enganosa ou abusiva capaz de induzir o consumidor ao erro. 
No entanto, estudo conduzido por Tinne (2013) já apontava que instituições de autorregulamentação da propaganda têm sido caracterizadas como um mecanismo insuficiente para supervisionar as práticas publicitárias, dada amplitude da responsabilidade e da lenta taxa de resposta das organizações. No Quadro 1 é possivel identificar pontos relevantes que estão em concordância com a NBR ISO 14.020 - Rótulos e declarações ambientais: princípios gerais (ABNT, 2002); a NBR ISO 14021 - Autodeclarações ambientais (ABNT, 2013); a NBR ISO 14024 - Rotulagem Ambiental do tipo 1: princípios e procedimentos (ABNT, 2004); o Código Brasileiro de Autorregulamentação Publicitária (CONAR, 2016) e o CDC (Brasil, 1990).

Arantes (2011) considera que no CDC pode-se destacar o direito à educação, informação e divulgação sobre o consumo adequado de produtos e serviços, assim como da forma de descarte ambientalmente correto dos resíduos produzidos. Neste ponto, observa-se a relevância desta lei para tratar, dentre diversos assuntos, a questão ambiental, incluindo sensibilização do consumidor e possiveis mudanças comportamentais. Assim, "as questões de proteção e defesa do consumidor e do meio ambiente estão intimamente relacionadas e interligadas, de modo que analisar a proteção ambiental dissociada dos valores do mercado e das relações de consumo é um equívoco" (Arantes, 2011, p. 170). Ainda no que diz respeito ao princípio da informação, a autora destaca que todas as pessoas possuem o direito de estarem informadas não apenas sobre características essenciais de um produto ou serviço, mas também acerca de questões ambientais envolvidas em seu processamento.

A partir da análise do Quadro 1, nota-se que as NBRs ISO 14.020, 14.021 e 14.024 e o Código do CONAR se somam ao CDC na medida que também não permitem declarações enganosas, exigindo que sejam verdadeiras, passiveis de verificação e comprovação, exatas, precisas, adequadas e claras. Além disso, assim como a Lei $n^{0}$ 8.078/90, as normas 150 e o código do CONAR estabelecem que os responsáveis pela declaração devem dispor de dados comprobatórios para dar sustentação à mensagem divulgada.

\section{ESTRATÉGIA METODOLÓGICA}

A pesquisa utilizou-se de métodos qualitativos, que de acordo com Bauer e Gaskell (2002), lidam com interpretações das realidades sociais. Além do levantamento de referências para embasar a análise empreendida, buscou-se inicialmente informações na Fundação de Proteção e Defesa do Consumidor de São Paulo - PROCON-SP2 para identificar casos relevantes de rotulagem ambiental que também eram objeto de estudo daquela instituição. Assim, a partir da lista de rótulos ambientais identificados pelo PROCON (2012), selecionou-se o produto Papel Neve Compacto, fabricado pela empresa Kimberly Clark. Esta seleção seguiu os critérios estabelecidos pelos autores que consistiram no grande destaque das declarações ambientais no rótulo e na divulgação de relatórios de sustentabilidade recentes, uma vez que estes são fontes de dados secundários relevantes.

A primeira etapa do trabalho consistiu em coletar informações que possibilitassem a compreensão dos discursos utilizados pela empresa, com foco na rotulagem ambiental do produto estudado. As informações do rótulo foram analisadas a partir das perguntas apresentadas pela CSR Europe (2008), que foram adaptadas para a presente pesquisa. A utilização dessas questões foi fundamental para análise do rótulo, pois elas estão de acordo com as normas estabelecidas pelas NBRs ISO 14020, 14021 e 14024 (ABNT, 2002, 2004, 2013), bem como pelo Código de Autorregulamentação Publicitária (CONAR, 2016) e pelo Código de Defesa do Consumidor (Brasil, 1990). Deste modo, com base na análise do rótulo, bem como por meio de informações obtidas no site da empresa, nos relatórios de sustentabilidade e em dados técnico-científicos levantados na bibliografia especializada, os autores puderam responder à lista de perguntas.

OS, Organizações e Sustentabilidade, 7(2), p. 25-42, Londrina, PR, jul./dez. 2019.

ISSN 2318-9223, http://www.uel.br/revistas/uel/index.php/ros/issue/view/1607/showToc 
A segunda etapa do trabalho buscou obter dados primários e secundários sobre as práticas socioambientais da empresa selecionada. Para tanto, além das consultas aos relatórios de sustentabilidade, foi realizada uma entrevista do tipo semiestruturada com o gerente de relações públicas da Kimberly Clark, que atuava na organização há dez anos. O conteúdo relevante para atender aos objetivos desta pesquisa foi devidamente transcrito pelo próprio entrevistador, como sugerem Belei et al. (2008) e Duarte (2004). Contudo, ressalta-se que não foram tratados todos os elementos executores de greenwashing, mas somente aqueles considerados importantes para compreender a relação entre as práticas e os discursos da empresa. Os resultados obtidos nessas duas etapas foram cruzados com a finalidade de examinar os discursos e as práticas da organização. Após o cruzamento de informações foi possível fazer uma discussão.

QUADRO 1 - EXIGÊNCIAS APRESENTADAS NOS DOCUMENTOS ANALISADOS

Exigências presentes nos documentos analisados

$\frac{\text { NBR ISO }^{1}}{140201402114024}$ CONAR $^{2}$ CDC $^{3}$

A informação não deve ser enganosa

Não é permitido apresentação de informações abusivas, que se aproveite da falta de experiência ou conhecimento do consumidor

Não é permitido apresentação de informações abusivas, que desrespeite valores ambientais A informação deve ser apresentada em língua portuguesa

A informação deve ser verdadeira e passivel de verificação e de comprovação, deve ainda ser exata, precisa, adequada e clara

As informações referentes aos procedimentos, metodologias e quaisquer critérios usados para dar suporte às declarações ambientais devem estar disponiveis e ser fornecidas a todas as partes interessadas sempre que solicitadas

As informações sobre aspectos ambientais dos produtos e serviços relevantes a declaração ambiental deve ser disponibilizada aos compradores e potenciais compradores

Deve haver clareza se a rotulagem ambiental é uma autodeclaração ou se está baseada em avaliação independente

A declaração ambiental deve ser relevante em termos de impacto total do produto, considerando todo o seu ciclo de vida

As alegações de benefícios socioambientais deverão corresponder a práticas concretas adotadas

Não é considerada pertinente a comunicação do mero cumprimento de disposições legais como um benefício socioambiental

As ações de responsabilidade socioambiental não devem ser comunicadas como evidência suficiente da sustentabilidade geral da empresa ou de seu produto

0 requerente do rótulo ambiental do tipo 1 (selo verde) deve estar em conformidade com a legislação ambiental e outras legislações pertinentes

Na rotulagem do tipo 1, os critérios ambientais que serão analisados devem ser baseados em indicadores originados das considerações sobre o ciclo de vida do produto

Na rotulagem do tipo 1, o desenvolvimento e a seleção dos critérios devem basear-se em sólidos princípios científicos e de engenharia

0 órgão responsável por conceder o selo verde deve garantir que sua marca de certificação/logotipo seja protegida legalmente, com o intuito de impedir o uso desautorizado e manter a confiança do público no programa

Uma declaração ambiental que seja vaga ou não específica, ou que implique amplamente que um produto seja ambientalmente benéfico ou ambientalmente benigno não deve ser utilizada. Ex: "amigo da natureza"

Não existem métodos definitivos para mensurar a sustentabilidade ou confirmar seu cumprimento. Deste modo, nenhuma declaração de sustentabilidade deve ser feita

Caso uma autodeclaração ambiental isolada tenha a probabilidade de resultar em malentendido, ela deve ser acompanhada de um texto explicativo

As autodeclarações ambientais e os textos explicativos devem ser apresentados de uma forma que indique claramente se a declaração se aplica ao produto completo ou apenas a um componente do produto ou da embalagem

As autodeclarações ambientais e os textos explicativos devem ser específicos quanto ao aspecto ou melhoria ambiental declarada

As autodeclarações ambientais e os textos explicativos não devem ser reafirmados

\begin{tabular}{c|c|c|c|c}
\hline & $X$ & $X$ & $X$ & $X$
\end{tabular}

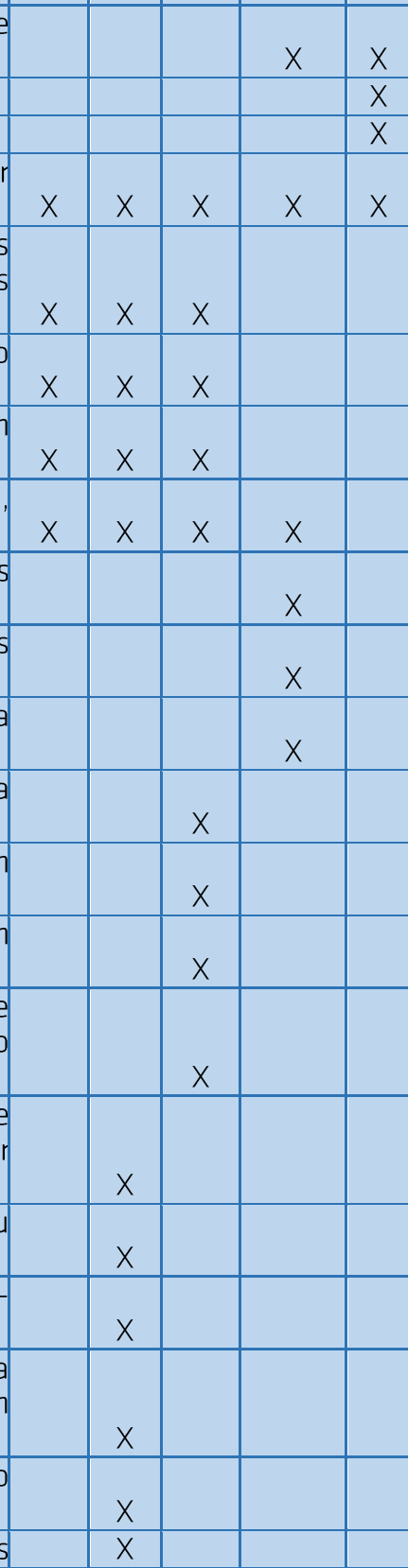

OS, Organizações e Sustentabilidade, 7(2), p. 25-42, Londrina, PR, jul./dez. 2019.

ISSN 2318-9223, http://www.uel.br/revistas/uel/index.php/ros/issue/view/1607/showToc 
utilizando-se uma terminologia diferente que implique diversos benefícios para uma única alteração ambiental

As autodeclarações ambientais não devem sugerir uma melhoria ambiental que não exista

Uma declaração não qualificada da capacidade de renovação deve ser feita somente quando o produto consistir em $100 \%$ de material renovável

Fonte: a partir de (1) ABNT (2002; 2004; 2013); (2) CONAR (2016); (3) Brasil (1990)

\title{
Apresentação e discussão dos resultados
}

A Kimberly Clark (KC) é uma empresa americana com operação em 37 países, sendo os seus produtos comercializados em 175 países (Kimberly Clark, 2015). A organização está presente no Brasil desde 1996 e é líder de mercado nas categorias de bens de consumo em que atua (Kimberly Clark, 2013), ofertando diversos produtos de higiene pessoal nas categorias de cuidados infantis, adultos e femininos, além de outras categorias e prestação de serviço, totalizando no país mais de 581 produtos e serviços ofertados (Kimberly Clark, 2015). No Brasil, a empresa opera em diversas localidades, porém chama-se a atenção para as unidades produtivas de Correia Pinto (SC), Camaçari (BA) e Mogi das Cruzes (SP), pois estas três unidades produzem o Papel Neve Compacto.

Com um faturamento bruto de $\mathrm{R} \$ 3,8$ bilhões em 2014, a empresa afirma ter investido $\mathrm{R} \$$ 11.138.333 em proteção ambiental, sendo somente 5,66\% referentes a custos de prevenção e 3,8\% a ações socioambientais (Kimberly Clark, 2015). A empresa ainda possui investimentos em projetos sociais voltados às comunidades do entorno das unidades de produção e aos principais grupos de clientes, particularmente mulheres e idosos; além disso, também incentivam o trabalho voluntário dos próprios funcionários nos projetos sociais e realizam doações de produtos, entre outras atividades (Kimberly Clark, 2015).

\section{RótULO AMBIENTAL: ANÁLISE GERAL dO DISCURSO E DAS PRÁTICAS AMBIENTAIS DA EMPRESA}

O rótulo do Papel Higiênico Neve Compacto está apresentado nas Figuras 1 e 2. Embora não seja um atributo ambiental, a informação "Compacto: basta apertar e pronto", presente na frente da embalagem (Figura 1), é sem dúvida o destaque do produto, pois é a partir desta característica que se tem o ciclo discriminado no verso da embalagem (Figura 2), aparentemente utilizado para responder a seguinte questão: "Por que o Neve Compacto faz bem ao planeta?" Assim, nesse ciclo é apresentado as seguintes afirmações, nesta ordem:

\begin{abstract}
Desde a sua concepção Neve Compacto foi pensado para diminuir o impacto ambiental. Neve só usa celulose de madeira de área de reflorestamento, preservando a floresta nativa. O produto é compactado por um processo moderno, não alterando a maciez e absorção de Neve. Permite uma economia média de 13\% de material plástico. Permite transportar, em média, $18 \%$ mais produtos no caminhão, reduzindo a emissão de gases do efeito estufa. Esta embalagem possui uma alça prática, dispensando o uso de sacolas plásticas.
\end{abstract}

Abaixo da imagem deste ciclo existe a seguinte afirmação: "Suave para sua pele, suave para o planeta". Logo após, se lê: "Neve se preocupa com o meio ambiente. Conheça nossas iniciativas sustentáveis". E assim, apresenta-se:

Por Um Brasil Mais Verde.

I'm Green, plástico: >56\% de fonte renovável. Verificado por ASTM 06866.

FSC Misto: Papel produzido a partir de fontes responsáveis. FSC C105374.

The Nature Conservancy: Proteger a natureza é preservar a vida.

Nesta última, uma explicação logo abaixo afirma que "o uso da marca The Nature Conservancy (TNC) não implica em endosso de qualquer produto, serviço ou atividade da Kimberly Clark". Tal afirmação merece considerações, pois segundo o código do CONAR os responsáveis pela

OS, Organizações e Sustentabilidade, 7(2), p. 25-42, Londrina, PR, jul./dez. 2019.

ISSN 2318-9223, http://www.uel.br/revistas/uel/index.php/ros/issue/view/1607/showToc 
publicidade devem dispor de fontes externas que endossem as informações ambientais divulgadas (CONAR, 2016).

Por fim, chama-se a atenção para a presença do símbolo em forma de triângulo com a inscrição do número 4 e logo abaixo a informação PEBD, indicando que o material é feito de Polietileno de Baixa Densidade. Segundo Wells (2006), tal símbolo não é considerado declaração ambiental: trata-se somente de uma identificação importante para auxiliar a separação dos diferentes tipos de plásticos. Cabe destacar que tal símbolo é amplamente utilizado pelo mercado em produtos e embalagens e pode contribuir para os esforços de reciclagem do material, uma vez que não é possivel reciclar diferentes tipos de materiais em um único processo.

FIGURA 1 - Rótulo dO PAPEL NeVE COMPACto - Frente dA EMBALAGEM

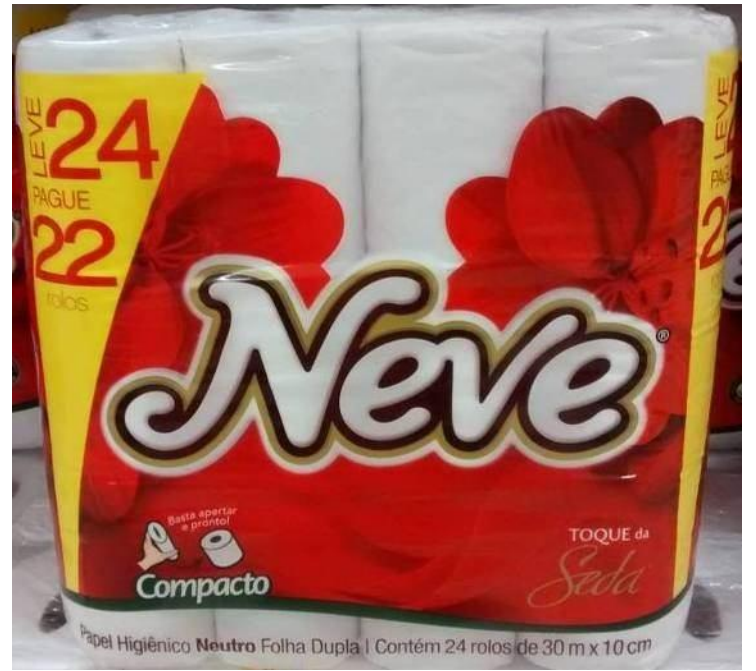

Fonte: a partir do próprio produto - imagem registrada em março de 2016.

\section{FIGURA 2 - RÓTULO dO PAPEL NEVE COMPACTO - VERSO dA EMBALAGEM}

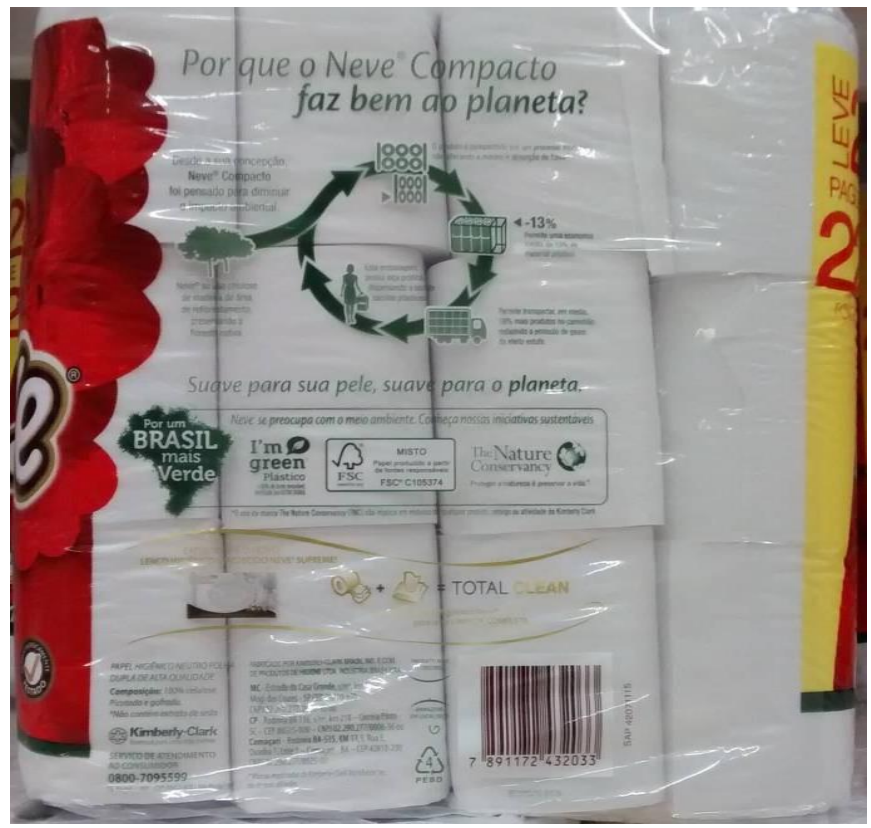

Fonte: a partir do próprio produto - imagem registrada em março de 2016.

De acordo com a Kimberly Clark (2011), a empresa utiliza a ferramenta denominada Design for Environment (DfE) para calcular o impacto do Papel Neve Compacto com base em cinco variáveis: 
consumo de água; emissão de poluentes; envio de resíduos para aterro sanitário; emissão de CO2; e consumo de combustível de origem fóssil. A análise destas variáveis gera uma pontuação para os produtos. Assim, o gerente da KC (2013) explica que "qualquer produto que pela ferramenta DfE tiver acima de 100 pontos é considerado sustentável". Ele ainda afirma que "o Neve Compacto tem 240 pontos, sendo o produto, dentro da corporação, considerado mais sustentável segundo esta ferramenta". Dentre as variáveis que o gerente da KC destaca para o papel Neve estão o reaproveitamento do refugo no processo produtivo da unidade de Mogi das Cruzes, a diminuição do consumo de água, a compactação do produto, a certificação FSC da celulose, e a embalagem plástica que possui matéria prima renovável (Cerente da KC, 2013).

Merece destaque a iniciativa da organização em buscar alternativas para a disposição final dos resíduos. Assim, afirma-se que "nenhum dos resíduos de processos de fabricação são aterrados desde setembro de 2014, tendo sido desenvolvidas soluções de reciclagem e de cogeração para que o aterro não seja mais necessário" (Kimberly Clark, 2015, p. 86). Acrescenta-se a este fato as caldeiras de biomassa utilizadas na unidade de Correia Pinto e recentemente instalada em Mogi das Cruzes, que reaproveitam parte dos resíduos da produção para geração de energia.

A compactação do papel higiênico otimizou a logística do produto e trouxe benefícios ambientais e econômicos para a organização. Deste modo, segundo a Kimberly Clark (2013), a compactação de 77\% da produção, no ano de 2012, permitiu uma redução de 815 toneladas de emissões de CO2, que seriam emitidas com o transporte dos produtos. Além disso, tal ação diminuiu os gastos com transporte e permitiu uma economia média de 13\% de plástico nas embalagens, o que corresponde a 84 toneladas deste material (Kimberly Clark, 2013).

No que diz respeito à otimização da logística, deve-se considerar não somente a redução das emissões de gases do efeito estufa, como também a redução das emissões de outros poluentes, que causam inúmeros prejuízos à saúde e à qualidade ambiental. A empresa declara que, apesar das dificuldades encontradas, tem buscado outras formas de transportar os seus produtos, por meio da utilização de caminhões maiores que permitem acomodar mais produtos, reduzindo assim as viagens e por meio de cabotagem (Kimberly Clark, 2015), transporte realizado entre os portos do país.

Ainda para análise do ciclo descrito no rótulo, há que se considerar que a embalagem de fato apresenta uma alça para facilitar o manuseio e o transporte do produto pelo consumidor. Porém, é importante destacar que tal alça, assim como a compactação do papel higiênico, são práticas adotadas por alguns concorrentes. Quanto à declaração de que "Neve só usa celulose de madeira de área de reflorestamento, preservando a floresta nativa", deve-se dizer que a produção de celulose se dá a partir de plantios comerciais e não de floresta nativa, tanto para garantir a qualidade do produto, como para atendimento ao órgão certificador (FSC), como ainda por força de lei, que não autoriza a utilização de floresta nativa para produção industrial. Vale lembrar, neste caso, que o princípio de pertinência do Anexo U do código do CONAR estabelece que "não serão considerados pertinentes apelos que divulguem como benefício socioambiental o mero cumprimento de disposições legais e regulamentares a que o anunciante se encontra obrigado" (CONAR, 2016).

\section{Selo Verde e Demais Autodeclarações}

A seguir na Figura 3 apresenta-se uma imagem extraída do rótulo do produto para destacar as declarações que serão tratadas nesta sessão.

FIGURA 3 - RÓTULO dO PAPEL NEVE COMPACTO - DESTAQUE PARA ALGUMAS DECLARAÇÕES AMBIENTAIS.

OS, Organizações e Sustentabilidade, 7(2), p. 25-42, Londrina, PR, jul./dez. 2019.

ISSN 2318-9223, http://www.uel.br/revistas/uel/index.php/ros/issue/view/1607/showToc 


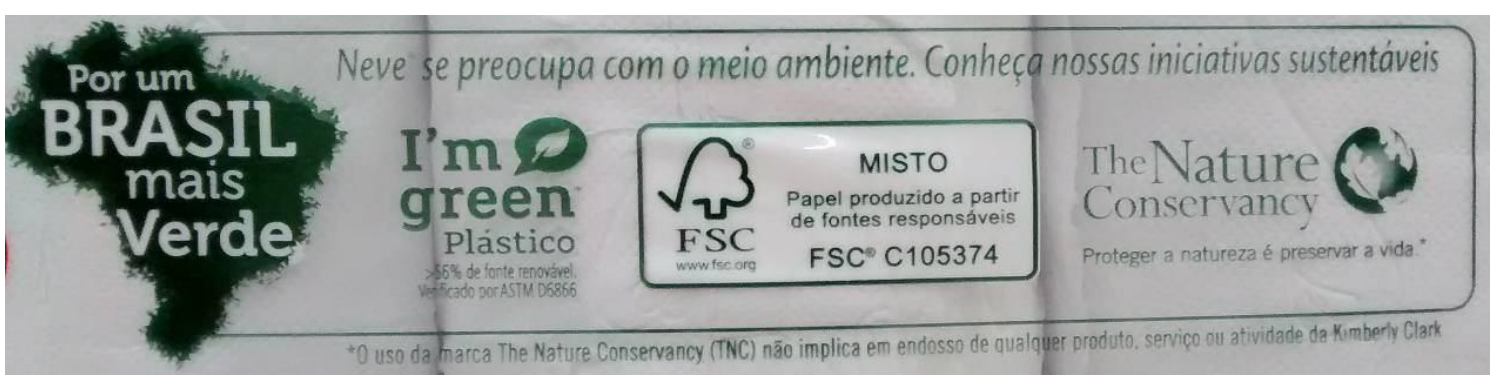

Fonte: a partir do próprio produto - imagem registrada em março de 2016.

A expressão "Por um Brasil mais Verde" refere-se a um conjunto de ações e estratégias que a empresa adotou e que englobam a certificação FSC, a parceria com a Braskem para a declaração I'm Green e com a ONG The Nature Conservancy. Cabe ressaltar que dos simbolos apresentados, somente o selo FSC Misto provém de certificação, ou seja, somente este é rotulagem do tipo 1 (selo verde), as demais imagens são autodeclarações da empresa e parcerias firmadas. Contudo, isso não é claro para o consumidor, que não consegue distinguir quais símbolos estão baseados em avaliação independente e quais se tratam de declarações realizadas pela empresa sem avaliação alguma. Tal fato está em discordância com os requisitos estabelecidos pela NBR ISO 14020. A declaração I'm Green vem acompanhada das seguintes informações: "> 56\% de fonte renovável"; "verificado por ASTM D6866". Estas declarações referem-se à embalagem que é feita com uma porcentagem de matéria prima renovável, polietileno proveniente da cana-de-açúcar. A utilização deste material permitiu uma redução de $43 \%$ do consumo de polietileno de fonte não renovável, resultando em uma diminuição de 2.700 toneladas de emissões de CO2 equivalente (KimberlyClark, 2013). Apesar das vantagens ambientais destacadas e da análise do material pelo método ASTM 06866 para verificar a porcentagem de matéria prima renovável, não se pode confundir a declaração "I'm Green" com um selo verde, pois esta foi criada pela própria Braskem, empresa que fabrica os plásticos e não provém de avaliação independente. Tal símbolo é amplamente utilizado no mercado, contudo, não deixa claro ao consumidor se tal declaração se refere ao produto ou a embalagem, caracterizando discordância em relação a norma da ISO 14021.

Arantes (2013) afirma que esta declaração também apresenta infrações ao Código de Defesa do Consumidor na medida em que para haver a utilização de termo em inglês, ou qualquer outra língua, deve haver a respectiva tradução para o português. No que diz respeito à declaração " $>56 \%$ de fonte renovável", deve-se considerar que "a explicação que segue é um complemento necessário ao apelo utilizado, mas que é insuficiente para demonstrar ao consumidor porque o produto/empresa é verde". Além disso, o sinal de ">" pode ser um complicador "pois muitos consumidores não conhecem seu significado, impedindo a aquisição do produto de forma responsável e consciente".

O selo FSC Misto, concedido por uma certificadora independente, visa oferecer uma garantia de que os produtos que possuem essa marca são provenientes de florestas bem manejadas, fontes controladas, materiais recuperados ou uma mistura deles (FSC, 2011). A utilização do selo FSC Misto exige que no mínimo $70 \%$ da matéria prima seja certificada, enquanto o restante do material pode vir de outras fontes não certificadas ${ }^{1}$, como é o caso das fontes controladas.

Contudo, não há clareza para o consumidor sobre a quantidade de material que é certificado, recuperado ou controlado no selo FSC Misto, tampouco há uma ampla divulgação de informações por parte do FSC - Forest Stewardship Council (Conselho de Manejo Florestal) e das certificadoras sobre como funcionam os selos FSC e quais as diferenças entre os tipos de selo FSC 100\%, Misto,

\footnotetext{
${ }^{1}$ Para obter mais informações é possivel consultar a norma FSC-STD-40-004 V2-1 POR de 2011 e o documento de Avaliação de Risco para Madeira Controlada FSC, versão FSC-CW-RA-020-BRA V1-1 de 2015, ambos disponíveis em: <https://br.fsc.org/pt-br/certificao/tipos-de-certificados>.
}

OS, Organizações e Sustentabilidade, 7(2), p. 25-42, Londrina, PR, jul./dez. 2019.

ISSN 2318-9223, http://www.uel.br/revistas/uel/index.php/ros/issue/view/1607/showToc 
entre outros. Tal fato demonstra uma limitação do selo FSC para garantir ao consumidor maior clareza na declaração. A Kimberly Clark (2011, p. 14 e 15) explica que:

\begin{abstract}
.. os produtos certificados são produzidos com uma mistura de matérias-primas que podem contemplar: celulose crédito misto, FSC 100\%, celulose FSC 70\% mínimo, refugos internos do próprio processo e material recuperado, de forma que a proporção de cada um resulte, no mínimo, no índice FSC pelo qual o produto é certificado.
\end{abstract}

Apesar do mencionado, ressalta-se a relevância da certificação e do selo FSC para incentivar técnicas de manejo florestais que estejam de acordo com a legislação. Com relação à declaração da The Nature Conservancy, Wells (2006) afirma que símbolos e dizeres relacionados a patrocínio de ONGs ou institutos não são considerados declarações ambientais segundo as normas da ISO, pois não se referem a um atributo ambiental do produto.

No que diz respeito ao Código de Defesa do Consumidor, cabem as mesmas observações sobre as limitações quanto a clareza da expressão em inglês. É importante salientar que embora a The Nature Conservancy seja uma ONG internacional que desenvolve trabalhos no mundo todo, não são todas as pessoas que a conhecem, e mesmo aos que a conhecem, não está claro qual é o tipo de parceria firmado entre a empresa e a ONG.

A empresa informou que assinou uma parceria com a TNC para medir a pegada hídrica da fábrica de Mogi das Cruzes. "O estudo será conduzido de modo a compensar a água utilizada no processo por meio de replantio da mata ciliar do sistema do Rio Tietê" (Kimberly Clark, 2013, p. 12). A parceria também visa contribuir para recuperação e conservação de 32 hectares de áreas críticas para a produção de água, incluindo nascentes e margens de rios da Bacia do Alto Tietê (KimberlyClark, 2015). Cabe destacar que a parceria da Kimberly Clark com a TNC está voltada somente para a unidade de Mogi das Cruzes, não contemplando as unidades de Correia Pinto e Camaçari, onde 0 Papel Neve Compacto também é produzido. Contudo, tal informação não está clara ao consumidor, que ao ver a marca da The Nature Conservancy no rótulo pode supor que a ONG atua em todas as unidades da empresa.

Por fim, com relação à declaração "Neve se preocupa com o meio ambiente. Conheça nossas iniciativas sustentáveis", nota-se que a empresa de fato possui práticas relevantes no contexto dos impactos ambientais de sua operação. Entretanto, é importante citar que tais ações geraram ganhos positivos para ela em termos de redução de custos, vantagem competitiva e melhoria da imagem.

\title{
Neve Faz Bem e é Suave para o Planeta?
}

No que diz respeito à pergunta "Por que o Neve Compacto faz bem ao planeta?", é importante dizer que a apresentação da ilustração em formato de ciclo induz o consumidor a entender que a descrição presente ali é suficiente para embasar a resposta a uma questão tão ambiciosa. Entretanto, é necessário considerar que sua produção possui diversos impactos ambientais negativos, resultantes da geração de resíduos e efluentes, da utilização de produtos químicos para branqueamento do papel, do consumo significativo de energia e água, entre outros. Por este motivo é difícil sustentar a argumentação de que faz bem ao planeta, apesar das práticas ambientais adotadas pela empresa.

A mesma argumentação aplica-se à expressão "suave para o planeta", que também é de difícil comprovação. Além disso, entende-se que tal expressão é ambígua e vaga, pois pode apresentar inúmeros significados de acordo com a percepção do consumidor. A associação dos termos pode induzir o consumidor a compreender que o produto gera pouco impacto ambiental, ou ainda que não gera impacto negativo, uma vez que ele faz bem ao planeta.

OS, Organizações e Sustentabilidade, 7(2), p. 25-42, Londrina, PR, jul./dez. 2019.

ISSN 2318-9223, http://www.uel.br/revistas/uel/index.php/ros/issue/view/1607/showToc 
Deve-se considerar ainda que ambas expressões estão em plena discordância com a norma da ISO 14020, que não permite declarações deste tipo, que induzam o consumidor a crer que o produto seja ambientalmente benéfico e sustentável e que possua qualidades ambientais que são inexistentes. Com a finalidade de melhorar a compreensão da discussão aqui empreendida, com base na lista de perguntas abordadas na metodologia, apresenta-se no Quadro 2 uma resposta sucinta às questões.

QUADRO 2 - RESPOSTAS ÀS QUESTÕES ORIENTADORAS DESTE TRABALHO

\begin{tabular}{|c|c|}
\hline $\begin{array}{l}\text { Questões propostas a partir da } \\
\text { formulação da CSR Europe }\end{array}$ & \\
\hline $\begin{array}{l}\text { A informação é verdadeira, precisa e } \\
\text { capaz de ser fundamentada? }\end{array}$ & $\begin{array}{l}\text { Parcialmente, pois expressões como "suave para o planeta", "Por que o Neve } \\
\text { Compacto faz bem ao planeta?" e "Por um Brasil mais verde" são de difícil } \\
\text { fundamentação, mesmo tendo como base as práticas ambientais adotadas } \\
\text { pela empresa. }\end{array}$ \\
\hline $\begin{array}{l}\text { A informação é relevante para o } \\
\text { produto em questão e para as } \\
\text { questões ambientais relacionadas a } \\
\text { ele? }\end{array}$ & Sim, totalmente. \\
\hline $\begin{array}{l}\text { Existe clareza sobre o problema } \\
\text { ambiental ou aspecto do produto a } \\
\text { que se refere? }\end{array}$ & $\begin{array}{l}\text { Parcialme } \\
\text { trata de } L \\
\text { uma unid }\end{array}$ \\
\hline $\begin{array}{l}\text { Os simbolos utilizados provem de } \\
\text { certificação de terceira parte? }\end{array}$ & $\begin{array}{l}\text { Parcialmente, pois } \\
\text { terceira parte, ou sej }\end{array}$ \\
\hline $\begin{array}{l}\text { A linguagem utilizada é simples e está } \\
\text { de acordo com o estabelecido pelo } \\
\text { código do consumidor? }\end{array}$ & $\begin{array}{l}\text { Parcialmente, pois existem textos em inglês e termos capazes de induzir o } \\
\text { consumidor ao erro. }\end{array}$ \\
\hline $\begin{array}{l}\text { As informações são vagas ou } \\
\text { ambiguas? }\end{array}$ & $\begin{array}{l}\text { Parcialmente, pois expressões como "Por um Brasil mais verde", "suave para } \\
\text { o planeta", "Por que o Neve Compacto faz bem ao planeta?", além da própria } \\
\text { logomarca da TNC, conferem ambiguidade intencional. }\end{array}$ \\
\hline 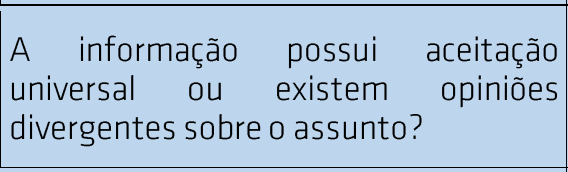 & $\begin{array}{l}\text { Para alguns elementos presentes no rótulo do produto existem opiniões } \\
\text { divergentes sobre o assunto. Como já apresentado, expressões que levem o } \\
\text { consumidor a crer que o produto é ecológico ou sustentável são passiveis de } \\
\text { contestação. }\end{array}$ \\
\hline $\begin{array}{l}\text { As informações dos atributos } \\
\text { ambientais do produto dizem respeito } \\
\text { a aspectos ambientais do produto ou } \\
\text { de sua produção ou não são } \\
\text { importantes para este tipo de } \\
\text { produto? }\end{array}$ & $\begin{array}{l}\text { As informações presentes no rótulo dizem respeito às características do } \\
\text { produto, como o "FSC Misto" e o "Compacto"; a produção, com o "The Nature } \\
\text { Conservancy"; a distribuição, com a explicação de que mais produtos são } \\
\text { transportados por caminhão; e a embalagem, com o "I'm Green" e a } \\
\text { explicação da alça de plástico contida na embalagem. }\end{array}$ \\
\hline $\begin{array}{l}\text { As informações sugerem que o } \\
\text { produto ou empresar possui } \\
\text { características ou ações ambientais } \\
\text { superiores aos dos concorrentes, } \\
\text { quando na verdade se trata de uma } \\
\text { prática comum? }\end{array}$ & $\begin{array}{l}\text { Parcialmente. O selo FSC Misto é amplamente utilizado em produtos feitos a } \\
\text { partir de celulose. A compactação dos rolos de papel higiênico vem sendo } \\
\text { adotadas por outras empresas do ramo, assim como a utilização de alças } \\
\text { plásticas na embalagem. }\end{array}$ \\
\hline $\begin{array}{l}\text { As informações são apresentadas com } \\
\text { uma linguagem que exagera as } \\
\text { qualidades e atributos que geram } \\
\text { benefícios ambientais? }\end{array}$ & $\begin{array}{l}\text { das práticas adotadas pela empresa e dos benefícios ambientais } \\
\text { não é possivel afirmar que o produto faz bem e é suave para o } \\
\text { npouco que as práticas contribuem com um Brasil mais verde. }\end{array}$ \\
\hline
\end{tabular}

Fonte: dados da pesquisa respondendo aos critérios da CSR Europe (2008)

\section{CONSIDERAÇÕES FINAIS}

O presente trabalho identificou que a empresa Kimberly Clark possui uma série de práticas relacionadas à responsabilidade socioambiental que, embora possam ser aprimoradas, sobretudo no sentido de abrangência, fazem parte da estratégia de negócio, inclusive de longo prazo. Para a pergunta: "a rotulagem ambiental presente no produto selecionado para estudo condiz com as

OS, Organizações e Sustentabilidade, 7(2), p. 25-42, Londrina, PR, jul./dez. 2019

ISSN 2318-9223, http://www.uel.br/revistas/uel/index.php/ros/issue/view/1607/showToc 
práticas adotadas pela empresa, ou se trata somente de greenwashing?" Admite-se que ela está de acordo com a maioria das práticas socioambientais adotadas pela empresa. Entretanto, a rotulagem possui elementos passíveis de contestação, com informações vagas, ambíguas, que por vezes exageram os benefícios ambientais do produto. Declarações como "suave para o planeta", "por que o Neve Compacto faz bem ao planeta?" e "por um Brasil mais verde" induzem o consumidor a pensar que o produto gera pouco impacto ambiental ou ainda que realmente faça bem para o planeta. Na verdade, toda a cadeia produtiva do produto gera impactos socioambientais negativos e significativos.

Ressalta-se que existem algumas declarações que apresentam problemas não apenas relacionados à Kimberly Clark, mas também às demais organizações que contribuem com as declarações do rótulo, concedendo os selos e símbolos, como é o caso do selo FSC Misto e da declaração I'm Green, que embora sejam amplamente utilizados em diversos produtos, não tornam claro para 0 consumidor quais são os aspectos tratados e qual é o seu real significado.

As evidências indicam que o rótulo poderia ser alvo de contestação pelo Código de Defesa do Consumidor e pelo CONAR. Por exemplo, o símbolo da The Nature Conservancy e o I'm Green, ambos em inglês, não apresentam informações complementares suficientes para a correta compreensão do leitor. O selo FSC, concedido por uma organização credenciada, também não possui clareza na informação prestada, de modo que poucos consumidores conseguem saber qual é o percentual de matéria-prima certificada.

Evidências também apontam que as exigências das NBRs ISO 14020, 14021 e 14024 não estão sendo plenamente cumpridas. A observação e atendimento de tais normas poderia contribuir para a melhoria das declarações ambientais, tornando as mensagens mais objetivas e de fácil compreensão, reduzindo ainda os possíveis vieses da comunicação. Com a aprovação da Lei $n^{0}$ 13.186, em 11 de novembro de 2015 (Brasil, 2015), que institui a Política de Educação para 0 Consumo Sustentável e estabelece entre seus objetivos o zelo pelo fomento à rotulagem ambiental e pelo direito a informação, espera-se que os problemas identificados diminuam e que os rótulos com apelos ambientais passem a ser melhor discutidos. Contudo, esta lei é incipiente e não trata das problemáticas envolvidas no discurso ambiental amplamente utilizado nas embalagens dos produtos.

Este trabalho traz contribuições para analisar e refletir sobre os discursos e as práticas ambientais, tendo identificado e destacado elementos do rótulo que podem ser aprimorados com a finalidade de atender a legislação, informar o consumidor e divulgar de forma mais clara as práticas ambientais da organização. É necessário mencionar que a presente pesquisa apresenta limitações, e uma delas se refere à necessidade de aprofundar a análise sobre todos os impactos ambientais e sociais ao longo da cadeia produtiva, envolvendo a obtenção da matéria prima, produção, transporte, consumo e pós-consumo. Outra limitação é que a análise se restringiu às fontes existentes: os relatórios de RSE e o rótulo da embalagem. Poderia ser oportuno verificar como o público consumidor percebe e compreende as alegações apresentadas na embalagem, e até que ponto elas interferem nas preferências de escolha pela marca e pelo produto.

Entretanto, tais limitações não diminuem a relevância do que a pesquisa revelou. Ao contrário: ela apresenta-se como um estímulo para que se ampliem as pesquisas e discussões sobre responsabilidade social e rotulagem ambiental no contexto brasileiro. Para tanto, é necessário que estas discussões venham acompanhadas de reflexões sobre conceitos amplamente utilizados e até certo ponto banalizados, como sustentável, ecológico, ecologicamente correto, verde e outros. É importante ampliar o debate e o entendimento sobre estes conceitos para que se possa definir o que é um produto sustentável, verde e ecologicamente correto.

OS, Organizações e Sustentabilidade, 7(2), p. 25-42, Londrina, PR, jul./dez. 2019. 


\section{REFERÊNCIAS}

ABNT (2002). ASSOCIAÇÃO BRASILEIRA DE NORMAS TÉCNICAS. NBR ISO 14020: Rótulos e declarações ambientais - princípios gerais. Rio de Janeiro.

ABNT (2013). ASSOCIAÇÃO BRASILEIRA DE NORMAS TÉCNICAS. NBR ISO 14021: Rótulos e declarações ambientais - Autodeclarações ambientais (Rotulagem do tipo II). Rio de Janeiro.

ABNT (2004). ASSOCIAÇÃO BRASILEIRA DE NORMAS TÉCNICAS. NBR ISO 14024: Rótulos e declarações ambientais - Rotulagem ambiental do tipo I - Princípios e procedimentos. Rio de Janeiro.

Antoniolli, G. \& Gonçalves-Dias, S. L. F. (2015). Uma discussão em torno de responsabilidade, comunicação ambiental e greenwashing: 0 caso da Petrobrás. Organizações \& Sustentabilidade, Londrina, 3(1), 3-46, jan./jun.

Arantes, A. B. (2013). Consulta Jurídica sobre informações e rótulos ambientais. Comunicação pessoal. Resposta enviada por e-mail em 01.06.2013.

Arantes, A. B. (2011). O novo dever anexo de informação dos fornecedores no mercado sustentável. Planeta Amazônia: Revista Internacional de Direito Ambiental e Políticas Públicas (3), 163-172. Macapá. Recuperado <http://periodicos.unifap.br/index.php/planeta/article/view/429/ArantesN3.pdf>.

Bauer, M. W., \& Gaskell, G. (2002). Pesquisa Qualitativa com texto, imagem e som: Um manual prático. Petrópolis: Editora Vozes.

Belei, R. A., Gimeniz-Paschoal, S. R., Nascimento, E. N., \& Matsumoto, P. H. V. R. (2008). 0 uso de entrevista, observação e videogravação em pesquisa qualitativa. Cadernos de Educação, Pelotas, 30, 187-199.

Blowfield, M. \& Murray, A. (2008). Corporate responsibility: a critical introduction. Oxford: Oxford University Press.

Borin, N., Cerf, D. C., \& Krishnan, R. (2011). Consumer effects of environmental impact in product labeling. Journal of Consumer Marketing, 28(1), 76-86.

Brasil. (2015). Lei $n^{0}$ 13.186, de 11 de novembro de 2015. Institui a Política de Educação para o Consumo Sustentável. Brasilia, 2015.2 Recuperado de: <http://www.planalto.gov.br/ccivil_03/_Ato2015-2018/2015/Lei/L13186.htm>.

Brasil. (1990) Lei $n^{0} 8.078$, de 11 de setembro de 1990. Dispõe sobre a proteção do consumidor e dá outras providências. Brasilia, $1990 . \quad$ Recuperado de: <http://www.planalto.gov.br/ccivil_03/leis//8078.htm>.

Bratt, C., Hallstedt, S., Robert, K., Broman, G., \& Oldmark, J. (2011) Assessment of eco- labelling criteria development from a strategic sustainability perspective. Journal of Cleaner Production, 19, 1631-1638.

Brito, A. M. (2013) Greenwashing: Matriz para o alinhamento entre comunicação organizacional e práticas ambientais. 155p. Dissertação (Mestrado em Comunicação). Universidade Municipal de São Caetano do Sul. São Caetano do Sul.

Bucci, E. (2008). ... Mas publicidade é informação? O Estado de São Paulo. Espaço Aberto, São Paulo, A-2, 19 jun 2008.

Bucci, E. \& Augusto Jr, S. N. (2012). A liberdade de imprensa e a liberdade na publicidade. Comunicação, mídia e consumo. São Paulo, 9(9), 33-48. 
Churchill, G. A. \& Peter, J. P. (2012). Marketing: Criando valor para os clientes (3 ed.). São Paulo: Saraiva.

CONAR. (2016). Código Brasileiro de Auto-regulamentação Publicitária. São Paulo: 2016. Recuperado de: <http://www.conar.org.br/>.

CSR Europe. (2008). CSR Europe's Sustainable Marketing Guide: '4Ps for 3Ps, 2008'. Recuperado de: <http://www.twosidesna.org/includes/files/upload/files/sustainablemarketingguide(1).pdf>.

De Boer, J. (2003). Sustainability labelling schemes: the logic of their claims and their functions for stakeholders. Bus. Strategy Environ., 12, 254-264.

Duarte, R. (2004) Entrevistas em pesquisas qualitativas. Educar, Curitiba, 24, 213-225.

Egria, C. P., \& Ralstonb, D. A. (2008). Corporate responsibility: A review of international management research from 1998 to 2007. Journal of International Management, 14(4), 319-339.

Eteokleous, P. P., Leonidou, L. C., \& Katsikeas, C. S. (2016). Corporate social responsibility in international marketing: review, assessment, and future research. International Marketing Review, 33(4), 580-624.

FSC. (2011). Forest Stewardship Council. FSC-STD-40-004 V2-1 POR: Norma para Certificação de Cadeia de Custódia FSC. 2011. Recuperado de: <https://br.fsc.org/pt-br/certificao/tiposdecertificados/cadeia-de-custdia-coc>.

FTC. (1992) U.S. Federal Trade Commission. 16 CFR Part 260 - Guides for the Use of Environmental Marketing Claims. Federal Covernment, USA.

Gonçalves-Dias, S. L. F. \& Teodódio, A. S. S. (2011). Perspectivas de análise do ambientalismo empresarial para além de demonizações e santificações. RGSA - Revista de Cestão Social e Ambiental, São Paulo, 5(2), 3-17, mai./ago.

Gonçalves-Dias, S. L.F., Guimarães, L. F., \& Santos, M. C. L. (2012). Inovação no desenvolvimento de produtos "verdes": integrando competências ao longo da cadeia produtiva. Revista de Administração e Inovação, 9, 129-153.

Greenpeace. (1992). The Greenpeace Book of Greenwash. Recuperado de: <http://research.greenpeaceusa.org/?a=view\&d=4588>.

Greer, J. \& Bruno, K. (1997). Greenwash: The reality behind corporate environmentalism. Penang, Malaysia: Third World Network, and New York: the Apex Press.

Hainmuller, J. \& Hiscox, M. J. (2015). Buying green? Field experimental tests of consumer support for environmentalism. SSRN Electronic Journal.

Ihlen, O., Bartlett, J. L., \& May, S. (2011). Corporate social responsibility and communication. In The Handbook of communication and corporate social responsibility. United Kingdom: John Wiley \& Sons, Inc.

Karliner, J. (2001). A Brief History of Greenwash. Recuperado de: <http://www.corpwatch.org/article.php?id=243>.

Kazazian, T. (2005). Haverá a idade das coisas leves: Design e desenvolvimento sustentável. São Paulo: Editora Senac São Paulo.

Kimberly-Clark Brasil. (2011). Relatório de Sustentabilidade da Kimberly-Clark Brasil Indústria e Comércio de Produtos de Higiene Ltda. Ano Base 2010. Recuperado de: < http://www.kimberlyclark.com.br/Novo/Pagina.aspx?n=relatorios-de-sustentabilidade>. 
Kimberly-Clark Brasil. (2013). Relatório de Sustentabilidade da Kimberly-Clark Brasil Indústria e Comércio de Produtos de Higiene Ltda. Ano Base 2012. Recuperado de: <http://www.kimberlyclark.com.br/Novo/Pagina.aspx?n=relatorios-de-sustentabilidade>.

Kimberly-Clark Brasil. (2015). Relatório de Sustentabilidade da Kimberly-Clark Brasil Indústria e Comércio de Produtos de Higiene Ltda. Ano Base 2014. Recuperado de: <http://www.kimberlyclark.com.br/Novo/Pagina.aspx?n=relatorios-de-sustentabilidade>.

Kirchhoff, S. (2000). Green business and blue angels. Environmental and Resource Economics, 15, 403-420.

Kleba, J. (2003). Adesão voluntária e comportamento ambiental de empresas transnacionais do setor químico no Brasil. Ambiente \& Sociedade, 6(2), jul. /dez.

Kolk, A. (2004). A decade of sustainability reporting: developments and significance. International Journal of Environment and Sustainable Development, 3(1), 51-64.

Lubbers, E. (2002). Battling big business: Countering greenwashing, infiltration, and other forms of corporate bullying. Monroe: Common Courage Press.

Marquis, C., Toffel, M., \& Zhou, Y. (2015). Scrutiny, norms and selective disclosure: a global study of greenwashing. Forthcoming in Organization Science. Recuperado de: <http://papers.ssrn.com/sol3/papers.cfm?abstract_id=1836472" |I "\#">.

OECD. (1997). Organization for Economic Cooperation and Development. Eco-labelling: Actual Effects of Selected Programmes. OECD/CD, 105, Paris.

Pagotto, E. L. (2013). Greenwashing: Os conflitos éticos da propaganda ambiental. Dissertação (Mestrado em Ciências) - Programa de Pós-Graduação em Mudança Social e Participação Política, Escola de Artes, Ciências e Humanidades - USP. São Paulo, SP.

PROCON. (2012). Relatório sobre a Comissão Técnica de Sustentabilidade e Responsabilidade Socioambiental. Fundação PROCON SP e respectivas atividades. OFÍCIO/FPDC/ DPE/020/2012. Documento interno (não publicado).

Reid, E. M., \& Toffel, M. W. (2009). Responding to public and private politics: corporate disclosure of climate change strategies. Strategic Management Journal, 30(11), 1157-1178.

Silva, E. A. (2011). Irresponsabilidade histórica: memória e reputação corporativa como um dos desafios para a sustentabilidade. IDEA, 2(2), jan-jul.

Tinne, W. S. (2013). Green Washing: An Alarming Issue. ASA University Review, 7(1).

Tokar, B. (1997). Earth for sale: Reclaiming Ecology in the age of corporate greenwash. Cambridge: South End Press.

Traies, S. (2005). Corporate sustainability: Greenwash or a path to sustainable capitalism? Tese de Doutorado. Deakin University, Australia.

Valle, C. E. (2004). Normas ISO 14000. In: Valle, C. E. Qualidade ambiental: ISO 14000. (5 ed.). São Paulo: Editora Senac São Paulo.

Wells, C. (2006). Rotulagem ambiental. In: VILELA JUNIOR, A. \& J. DEMAJOROVIC (orgs.) Modelos e ferramentas de gestão ambiental: Desafios e perspectivas para as organizações. (2 ed.). São Paulo: Editora Senac São Paulo.

Werther, W. B. \& Chandler, D. A. (2006). Strategic corporate social responsibility. New York: Sage Publications. 
Whitson, D., Ozkaya, H. E., \& Roxas, J. (2014). Changes in consumer segments and preferences to green labelling. International Journal of Consumer Studies, 38, 458-466. 